\title{
New ethical requirements at the NIH: implications for CIHR and Canada
}

$T$ he post-Enron era has been characterized by increased public demand for accountability and transparency. This new environment of accountability has created fresh challenges for the publicly funded research community, for funders as well as for the individuals and institutions doing research. Events in recent months have focused the attention of the US public and legislators on conflicts of interest in the health research community, leading to the introduction of stringent new conflict-of-interest guidelines for the US National Institutes of Health (NIH). I wish to discuss this new US landscape and its possible implications for Canadian health research.

The public reasonably expects that agencies, their boards and executives place the public's interests first, above personal or institutional benefit, when investing public funds. There is also an expectation that the public interest, rather than commercial or individual interests, will guide the funding decisions of the government and its agencies.

Developments, both scientific and political, in the past few decades are nonetheless blurring the separation between public and commercial interests. Governments have been actively encouraging researchers and institutions to commercialize the results of publicly funded research, as a justification for increasing public investments in research. In the United States, the Bayh-Dole Act of 1980 has greatly facilitated interactions between industry and academia, while in Canada, universities, hospitals and funders have publicly committed to increase considerably the transfer of new technologies to the private sector. Health research also increasingly involves the active exchange of reagents, databases and technologies between the academic and private sectors. From clinical trials to largescale proteomics, the barriers between academia and industry are falling, reflecting the new realities of modern health research.

In 1995 , in an effort to attract and retain senior NIH researchers and directors and to encourage academic-industrial interactions, Harold Varmus, then director, relaxed NIH policies then in place, allowing senior employees to consult and receive money, stock and stock options in return for their advice. But with increasing attention and criticism from the media, times have changed; for example, a recent series of articles by a Los Angeles Times reporter alleged (among other things) that a full-time NIH employee helping to draft US national cholesterol guidelines received US\$140 000 from companies making or developing cholesterol drugs. ${ }^{1}$

Under pressure from Congress, the US Department of Health and Human Services (the source of NIH budgets) published new regulations on conflicts of interest. As the new rules required, Dr. Elias A. Zerhouni, Director of the NIH, in March 2005 instituted stringent new requirements for ethical conduct and financial disclosure for NIH employees. ${ }^{2}$ These new rules prohibit all $6000 \mathrm{NIH}$ employees (and in some instances, their spouses) from activities and investments such as receiving any compensation from the private sector or from research institutions that receive NIH grants, and from holding stock in biopharmaceutical companies. The NIH is also currently reviewing conflict-of-interest policies for volunteers who serve on its advisory boards and study sections or grants panels, to ensure that budget allocations are free of bias.
Reactions to the new rules have been mixed; many scientists have wondered whether the pendulum has swung too far. At least 3 prominent NIH researchers are leaving the NIH for positions at major US universities. The US Congress is holding hearings to consider whether the new guidelines are excessive. Finally, Dr. Zerhouni has called for an ethics summit to have an open discussion on conflict-ofinterest rules in universities and other public institutions.

What does all of this mean for Canada, and for the 13 Canadian Institutes of Health Research (CIHR)? CIHR's "virtual institute" structure means that its 13 scientific directors and the 230 members of our 13 Institute Advisory Boards are involved in governing, advising on and administering research funds. This involvement is one of CIHR's strengths; it helps to ensure that CIHR is connected to leadingedge research and is hence better able to develop a strategic research agenda. At the same time, CIHR's unique structure, with individuals having dual roles as researchers and funders, raises the potential for real or perceived conflicts of interest.

CIHR's conflict-of-interest policy (2000; available at www .cihr-irsc.gc.ca/e/19039.html) applies to all personnel, including members of the governing council and officers, and all staff paid directly by CIHR. Also included are our scientific directors and their support staffs, all of whom are paid through their host academic institutions, and members of the Institute Advisory Boards. Overlaying this internal policy is the federal government's Values and Ethics Code for the Public Service, ${ }^{3}$ a document that applies to CIHR officers and staff.

Taken together, these policies provide a comprehensive set of rules governing disclosure of 
interests and assets, outside employment, solicitation and acceptance of gifts and benefits, preferential treatment and use of insider information. The net result is that paid and unpaid personnel are required to arrange their private affairs in a manner that will prevent real, potential or apparent conflicts between their private interests and their official duties. Wherever a conflict arises, it must be disclosed and resolved in favour of the public interest.

What about members of the health research community with no direct link to CIHR? The Tri-Council Policy Statement: Ethical Conduct for Research Involving Humans (available through www .nserc.ca/institution/mou_e.htm as schedule 2) is the framework that governs research involving people as subjects. The 3 Canadian federal agencies that provide Tri-Council funding CIHR, the Natural Sciences and Engineering Research Council of Canada and the Social Sciences and Humanities Research Council of Canada - will accept applications only from individuals and institutions that comply with this policy. Research institutions formally agree to adhere to this policy statement when they sign the Memorandum of Understanding on Roles and Responsibilities in the Management of Federal Grants and Awards (2002; available at www.nserc.ca/institution/mou_e .htm), which describes the basic requirements for obtaining and maintaining institutional eligibility to administer agency funds.

CIHR requires the institutions that we fund to develop and maintain relevant institutional policies on specific issues such as conflict of interest. To reinforce this requirement, the memorandum of understanding will include a schedule on conflicts of interest, now being finalized by the 3 Tri-Council agencies. It will require institutions to have written policies for effective management of situations involving conflicts of interest in place by December 2006. They are also expected to put in place a structure for reporting and reviewing disclosures of interest conflicts, including (but not limited to) those related to finances and start-up companies in which the institution or any of its employees or officials have an interest.

A CIHR meeting in 2004 on institutional conflicts of interest recommended that institutions keep research involving human subjects strictly separated from investment management and technology licensing. It also called for institutional conflictof-interest committees to be implemented and a standard contract to be developed to govern university-industry relationships across Canada.

In short, the Canadian approach currently places the onus on host institutions to have appropriate policies and implementation procedures in place that deal with issues pertaining to conflicts of interest. Given current events in the United States, we might be wise to anticipate changes here in the public mood and to adopt a more proactive, pan-Canadian approach to these issues.

CIHR will continue to work with the other 2 members of the Tri-Council and our other partner institutions to facilitate the development of a harmonized set of principles and policies across Canada. A common na- tional approach is the best way to ensure transparency and accountability and also to facilitate multisite research.

CIHR recognizes that the solution to conflict-of-interest issues is not to divorce the public and private sectors. Indeed, as noted above, public-private partnerships are now a cornerstone of health research and its applications. But it is our collective responsibility, and it is in our collective interest, to address promptly and transparently all real and perceived issues of conflict of interest. Disclosure, transparency and selected prohibitions are all essential elements of a comprehensive approach to protect the public interest and ensure continued confidence in Canada's health research enterprise.

\section{Alan Bernstein}

President

Canadian Institutes of Health

Research

Ottawa, Ont.

Competing interests: None declared.

Acknowledgements: I thank Dr. Burleigh Trevor-Deutsch for his help in preparing and revising this paper.

\section{References}

1. Willman D. New rules will cost dissidents at NIH. LA Times 2005 Mar 3. Available: www.latimes.com/features /health/medicine/la-na-nih 3 mar03,1 ,6922975.story? coll=la-health-medicine \&ctrack $=1 \&$ cset $=$ true $($ accessed 2005 Jun 7).

2. Department of Health and Human Services. Supplemental standards of ethical conduct and financial disclosure requirements for employees of the Department of Health and Human Services: interim final rule with request for comments. Fed Regist 2005; 70:5543-65.

3. Treasury Board of Canada Secretariat. Values and ethics code for the public service. Ottawa: The Board; 2003. Available: www.tbs-sct.gc.ca/pubs_pol /hrpubs/TB_851/vec-cve_e.asp (accessed 2005 Jun 7). 